\title{
Interpersonal Function of the Linguistic Taboo
}

\author{
Yao Zhao, Wei Zhang* \\ Foreign Languages College, Beihua University, Jilin 132013, China
}

Keywords: Linguistic taboo, interpersonal function

\begin{abstract}
The linguistic taboo, as a part of language, is prohibited to be violated according to the linguistics. With the development of human society, it evolves new functions. The thesis, on the basis of the functional linguistics, analyzes the interpersonal function of linguistic taboos and reveals that the linguistic taboo does not only regulate the participants' speech act by observance, but also has various function by violation, such as to strengthen power and intensity, to relieve spiritual tension, to indicate attitude and to relieve spiritual tension.
\end{abstract}

\section{Introduction}

Taboo, as a negative sanction whose infringement results in an automatic penalty without human or superhuman mediation, refers to a powerful restriction or prohibition between specific categories of individuals and things in particular circumstance (Steiner, 1956:145).

The linguistic taboo, as a form of socially unacceptable expressions in the human community, is the verbal displacement for the certain object, events and concepts which tradition or social custom strongly frowns on their use and roundabout expressions are substituted. The original research mainly focused on ethnography, anthropology, sociology and psychology (Sigmund Freud 1913, A. L. Kroeber 1925, Margaret Mead 1967, T. Sophen1979), discussing about origins, restrictions, ambivalent social attitudes and its effect. Due to its sensitive nature, the sociolinguists began to research the linguistic taboo from the perspective of society, culture and euphemism (Hudson 1980, Peter Trudgill 1983, Ronald Wardhaugh 1986, Philip Thody 1997 etc.) since 1960s. Chinese scholars (Chen Wangdao 1979, Chen Yuan 1980, Chen Jianmin 1986 etc.) discuss linguistic taboos from the relationship between language and society in several pages. However, most works are involved in the relationship between language and culture, that is, static description. The thesis aims at the social and interpersonal function of the linguistic taboo with a dynamic perspective on the basis of the functional linguistics.

\section{The Origin of Linguistic Taboos}

The linguistic taboo is actually an integral part of language, the symbol of the world. In this sense, the linguistic taboo is both a linguistic and, more importantly, a social phenomenon. Therefore, to figure out origins which cause the linguistic taboos clearly is prerequisite to analyze its function.

Word Fetishism: Sir James George Frazer states that "Unable to differentiate between words and objects, the savage generally imagines that the link between a name and the nominated object or subject is not a mere arbitrary and ideological association but a true and substantial bond......”. (Frazer: 1963) These conceptions of the nature of words inevitably led to word-fetishism: the worship of language as something bearing the power of punishing or rewarding. In primitive times, it is hard for ancient human beings to know the nature of language well as to understand terrible natural phenomena which seemed to possess certain supernatural force distributing inconvenience or even disasters. The naturalists set up an intrinsic correspondence between sound and sense, same as between language and object, language and referents. Consequently, language gradually signifies something mysterious and magical which can bring its users fortune and misfortune.

Psychological Factor: The connotative meaning refers to what is communicated by virtue of what language refers to and reflective meaning means what is communicated through association with another sense of the same expression (Leech, 1974.10-27). The connotative meaning is 
produced from psychological association, which causes the creation of linguistic taboos. The negative or positive feelings associated with the referent or the concept are provoked by word selection of the psychological factor, such as taboos concerning sex, body function and body excretions with the exception of tears and perhaps sweat, emerge from psychological factors.

Politeness Factor: In order to achieve an agreement in a conversation, certain words which might cause failure or hurting face should be clear. The desire to achieve mutual understanding in communication and make communication succeed leads to the indirect way expressing their thoughts, which is the politeness factor for linguistic taboos. This also follows Grice's Cooperative Principle (CP) and Leech's Politeness Principle (PP). The words referring to physical shortcomings, poverty, political and social stratification are tabooed mainly for the sake of showing politeness or sympathy to the others.

Homophonic Factor: The word, which has not semantic relation with linguistic taboos, becomes the linguistic taboo just due to homophonic style, that is, sounds of some words appear to be the same or similar to those of linguistic taboo words. It indicates that many linguistics taboo phenomena are generated from homophonic situation, most common in bilingual communication.

Cultural Factor: The linguistic taboo is a social cultural activity. Its creation is, and has been closely related with culture of a particular society including religion, values, social conventions and some other special purposes etc.

\section{Characteristics of Linguistic Taboos}

Universality, as the key phenomena of linguistic taboos, refers to the fact that linguistic taboo exists widely in every language and culture and regulates the speech act effectively. Then it must be clear that the universality is not absolute, but relative. Standards are constantly changing. The linguistic taboo, generated from one culture could be suitable in another. Yesterday's taboos can be today's slang and then may become common words tomorrow.

Modifiability refers that the linguistic taboo is relatively stable. It changes diachronically in periods and synchronically in certain circumstances. "First the occasional and later the frequent use of taboo words reduces their tabooedness. Once these words are no longer censured, their use becomes merely a matter of taste or style.”(Salzmann, 1993.194) New taboos may also appear. In fact, it is a circle from taboo words to euphemism and other taboo words again.

Uniqueness: The linguistic taboo can be reflected by the racial culture. The differences in historical evolution, social principle, value concept, convention and living style between the East and West cause the linguistic taboo different in content and style. In English, the words concerning privacy topics, such as religion, crime, women liberation, drug abuse, are tabooed, while in Chinese the address form is really complicated and sensitive, same as the topic concerning sex.

\section{Interpersonal Function of Linguistic Taboos}

As one of the Metafunction, the interpersonal function enacts social relationships, embodies all users of language to express social and personal relations. In communication, no matter what the addresser wants to express and imply, all can be illustrated by the way he chooses according to the context of situation. Actually the speakers' attitude and opinion in a speech act and the scale about polarity and modality have great concern with the topic of linguistic taboos analysis. This section is to analyze the interpersonal function of linguistic taboos according to the theory of context of situation.

To strengthen power and intensity

Some words are obviously taboos in common life. Participants in certain settings use those words to strengthen power and intensity.

For example, the word "bloody" in "Not bloody likely" in1962 is a strictly tabooed word because its association with "Christ's blood". Then, it has been used among the lower classes, however, the educated consider it as "a horrible word". Here the word "bloody" was used to strengthen the mood and express the narrator's emotion without any intention to offend body 
individually. It is considered normal for people to utter a strong oath or a taboo word at such moments. Using taboo words under such circumstances would not be evaluated as negatively as when they are used elsewhere. Due to linguistic taboos' nature, the linguistic taboo has a mysterious and unimaginable power. It is used to strengthen power and intensity in communication or to vent one's pent-up feelings.

To relieve spiritual tension

Individuals may use taboo words to vent pent-up emotions such as anger, pressure or frustration, especially when encountering unpleasant, frustrating and irritating situation. If people have stressful occupations or keep staying in stressful condition, they tend to relieve their tensions by using taboo words more. That is also the reason why there is a high degree of taboo word use among these men working on board since such work was quite dangerous and stressful.

To indicate attitude

The linguistic taboos could be used in some formal situations to indicate the opinion or the attitude of the speaker or the writer.

The simplest example is die or pass away. The word die is a strictly tabooed word both in English and Chinese. The word "die" in "Chiang Kaisheck died." "Khrushchev died." means much than merely "stop living”. It embodies a strong expression of disdainful and contemptuous attitude toward the dead. Pass away in "Master Hong passed away." is a euphemism, which is always followed by some other complimentary remarks such as "live in our hearts forever" or "great loss". In this formal setting, the linguistic taboo has the function to indicate the addresser's attitude to the addressee in the communication.

To reveal the relationship

As members of social group, the participants in the communication are not isolated individually. One of language's functions is to act as a symbol of a group identity. Linguistic taboo's observance and violation can reveal the relationship between participants in communication. For example, the workers in factories stay together every day and have same social status. Therefore, the relationship is more intimate than others. In daily greeting, certain taboo words are used to show the acquaintance and intimacy. The situation in the government is rare because of the relationship concerning power and solidarity. Another example, a girl tells another girl, "You'd better loose your weight." If they are best friends, this sentence will be taken as a suggestion or a joke. It is acceptable according to the degree of intimacy of the relationship. If a stranger utters it, it will be much offensive because it may mean a criticism of the girl's figure.

\section{Conclusion}

Linguistic taboos, as a part of language, change with the development of human society to satisfy human need for communication, are closely related to the culture of a society and the specific context in which they are used. It is not prohibited any longer in various contexts. The thesis, on the basis of the functional linguistics, analyzes the interpersonal function of linguistic taboos and reveals that the linguistic taboo does not only regulate the participants' speech act by observance, but also has various function by violation, such as to strengthen power and intensity, to relieve spiritual tension, to indicate attitude and to relieve spiritual tension.

* This Paper is based on the " $11^{\text {th }}$ Five-Year Plan" research program in humanities and social sciences "The Interpretation of Power and Solidarity from the Appraisal Perspective" [No.2007-274], conducted by Jilin Provincial Education Department.

\section{References:}

[1] Frazer, James George, The Golden Bough. [M]London: Macmillan \& Company Limited, 1963

[2] Halliday, M.A.K. An Introduction to Functional Grammar.[M] London: Edward Arnold. 1994

[3] Leech, G. Semantics: The Study of Meaning, [M]2 nd edn. Harmondsworth: Penguin, 1974

[4] Salzmann, Zdenek. Language, Culture \& Society. [M]Boulder: Westview Press Inc,1993. 
[5] Steiner, Franz. Taboo, [M]London: Cohen \& West Limited, 1956T.Hedge, Teaching and Learning in the Language Classroom, Shanghai Foreign Language Education Press, 2002.

[6] Wardhaugh,R. An Introduction to Sociolinguistics, [M]Blackwell Publishers Ltd., 2000 